\title{
DIELECTRIC-RESONATOR-LOADED MICROSTRIP ANTENNA FOR ENHANCED IMPEDANCE BANDWIDTH AND EFFICIENCY
}

\author{
Jacob George, ${ }^{1}$ C. K. Aanandan, ${ }^{1}$ P. Mohanan, ${ }^{1}$ K. G. Nair, ${ }^{1}$ \\ H. Sreemoolanathan, ${ }^{2}$ and M. T. Sebastian ${ }^{2}$ \\ ${ }^{1}$ Department of Electronics \\ Cochin University of Science and Technology \\ Cochin 682 022, Kerala, India \\ ${ }^{2}$ Regional Research Laboratory \\ Trivandrum, Kerala, India
}

Received 10 September 1997

ABSTRACT: $A$ new method for enhancing the 2:1 VSWR impedance bandwidth of microstrip antennas is presented. Bandwidth enhancement is achieved by loading the microstrip antenna by a ceramic microwave dielectric resonator $(D R)$. The validity of this technique has been established using rectangular and circular radiating geometries. This method improves the bandwidth of a rectangular microstrip antenna to more than $10 \%(\approx 5$ times that of a conventional rectangular microstrip antenna) with an enhanced gain of $1 \mathrm{~dB}$. (C) 1998 John Wiley \& Sons, Inc. Microwave Opt Technol Lett 17: 205-207, 1998.

Key words: antennas; microstrip antenna; bandwidth; dielectric resonutor

\section{INTRODUCTION}

Microstrip antennas find far-reaching applications in the current communication scenario due to their unique properties like light weight, ease of fabrication, low production cost, low profile, etc. The fields of application of these antennas are mainly limited by their inherent disadvantage of low-impedance bandwidth. Two commonly used microstrip radiating geometries are rectangular and circular. Techniques are available in the literature for improving the impedance bandwidth of microstrip antennas [1-4]. However, these methods will increase the complexity of the system or, in most of the cases, reduce the antenna gain.

In this letter, a method for improving the impedance bandwidth of a microstrip antenna using a dielectric res- 
onator attached on the surface of the patch is proposed. This technique improves the impedance bandwidth, to more than $10 \%$ for a rectangular microstrip antenna.

\section{DESIGN AND EXPERIMENTAL DETAILS}

The schematic diagram of a typical antenna configuration is shown in Figure 1 (a magnified view of the cylindrical DR used is also shown). The configuration consists of a rectangular patch of length $L$ and width $W$ on a substrate of thickness $h$ and dielectric constant $\epsilon_{r}$. The antenna is loaded with a cylindrical dielectric resonator of diameter $d$, height $H$, and dielectric constant $\epsilon_{d r}$. The patch is fed by a probe at the position $\left(X_{p}, Y_{p}\right)$. The operating frequency of the antenna is selected to be close to the $\mathrm{TE}_{01 \delta}$ mode resonant frequency of the dielectric resonator.

A rectangular microstrip antenna resonating at $2.70 \mathrm{GHz}$ ( $L=2.58 \mathrm{~cm}, W=3.35 \mathrm{~cm}, h=0.16 \mathrm{~cm}, \epsilon_{r}=4.5$ ) is designed for optimum radiation performance [5]. A cylindrical $\mathrm{DR}\left(H=0.9 \mathrm{~cm}, d=1.4 \mathrm{~cm}, \epsilon_{d r}=58\right)$ having $\mathrm{TE}_{01 \delta}$ mode frequency close to the resonating frequency of the above antenna is suitably positioned on the patch surface. The patch width, position of the DR on the patch, and the feed point are optimized experimentally for maximum impedance bandwidth, and the DR is pasted at this position using a thin layer of conducting epoxy. This typical configuration gives a maximum bandwidth of $274 \mathrm{MHz}$ at $2.63 \mathrm{GHz}$ when $L=2.58$ $\mathrm{cm}, W=2.94 \mathrm{~cm}, X_{p}=1.98 \mathrm{~cm}, Y_{p}=0.0 \mathrm{~cm}$, and the DR is placed at the middle of the nonradiating edge in such a way that its surface just grazes the radiating patch edge as shown in Figure 1. The variation of percentage bandwidth with feed location is shown in Table 1 . When the patch is fed at $(2.58$, 0 ), the system was not at all matched. But on loading with DR, the antenna is found to be matched, and provides an impedance bandwidth of more than $8 \%$. This shows that this technique can be used for the impedance tuning of microstrip antennas.

The experiment is repeated on a circular microstrip antenna resonating at $4.01 \mathrm{GHz}$ (radius $=1.42 \mathrm{~cm}, \epsilon_{r}=2.2$, $h=0.08 \mathrm{~cm})$ with a DR $\left(H=0.565 \mathrm{~cm}, d=0.979 \mathrm{~cm}, \epsilon_{d r}=\right.$ $63, \mathrm{TE}_{01 \delta}$ mode frequency $4.0 \mathrm{GHz}$ ). Here, the position of the DR on the patch surface and the feed point are experimentally optimized for maximum bandwidth. The configuration gives a maximum bandwidth of $239 \mathrm{MHz}$ at $3.92 \mathrm{GHz}$ when the feed point is at a distance of $1.00 \mathrm{~cm}$ and the DR center is at a distance of $1.21 \mathrm{~cm}$ from the patch center. The sector angle formed between two radial vectors, one passing

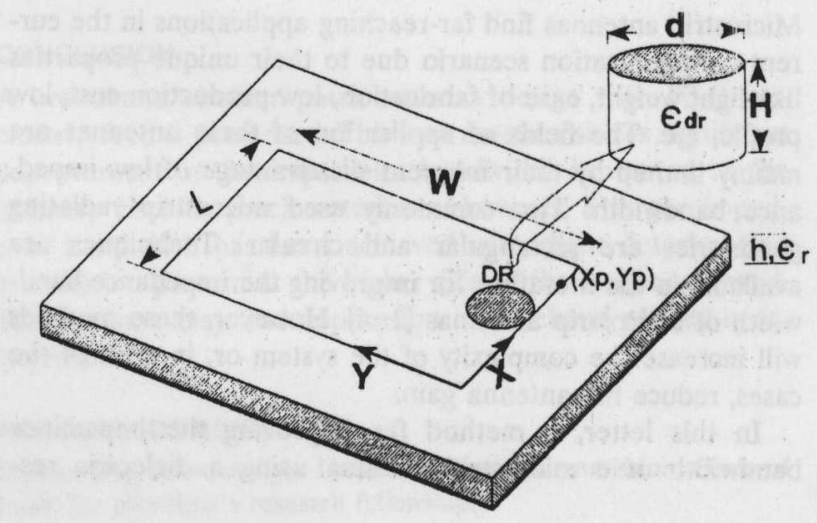

Figure 1 Schematic diagram of a typical antenna configuration
TABLE 1 Variation of Impedance Bandwidth with Respect to Feed Location for the Experimentally Tuned Rectangular Microstrip Antenna Configuration

\begin{tabular}{|c|c|c|}
\hline \multirow{2}{*}{$\begin{array}{c}\text { Feed Point } \\
\left(X_{p}, Y_{p}=0\right) \\
X_{p}(\mathrm{~cm})\end{array}$} & \multicolumn{2}{|c|}{ \% Bandwidth } \\
\hline & $\begin{array}{c}\text { Before DR } \\
\text { Loading (\%) }\end{array}$ & $\begin{array}{c}\text { After DR } \\
\text { Loading (\%) }\end{array}$ \\
\hline 2.58 & a & 8.90 \\
\hline 2.43 & a & 8.15 \\
\hline 2.28 & a & 8.10 \\
\hline 2.13 & a & 10.10 \\
\hline 1.98 & 2.2 & 10.41 \\
\hline 1.83 & 2.2 & 8.20 \\
\hline 1.68 & 3.3 & 7.21 \\
\hline 1.53 & 3.3 & 6.84 \\
\hline
\end{tabular}

${ }^{a}$ Not matched.

TABLE 2 Characteristics of the DR-Loaded Rectangular and Circular Microstrip Antenna Configurations

\begin{tabular}{lcc}
\hline Characteristic & $\begin{array}{c}\text { Rectangular } \\
\text { Patch }\end{array}$ & $\begin{array}{c}\text { Circular } \\
\text { Patch }\end{array}$ \\
\hline Substrate dielectric constant & 4.5 & 2.2 \\
Resonance frequency without DR & $2.70 \mathrm{GHz}$ & $4.01 \mathrm{G}$ \\
$\%$ bandwidth (VSWR $\leq 2)$ without DR & $2.2 \%$ & $1.1 \%$ \\
\% bandwidth (VSWR $\leq$ 2) with DR & $10.41 \%$ & $6.1 \%$ \\
Central frequency with DR & $2.63 \mathrm{GHz}$ & $3.92 \mathrm{GH}$ \\
3 dB beamwidth & & \\
$E$-plane & $128.7^{\circ}$ & $109.8^{\circ}$ \\
$H$-plane & $71.2^{\circ}$ & $79.5^{\circ}$ \\
\hline
\end{tabular}

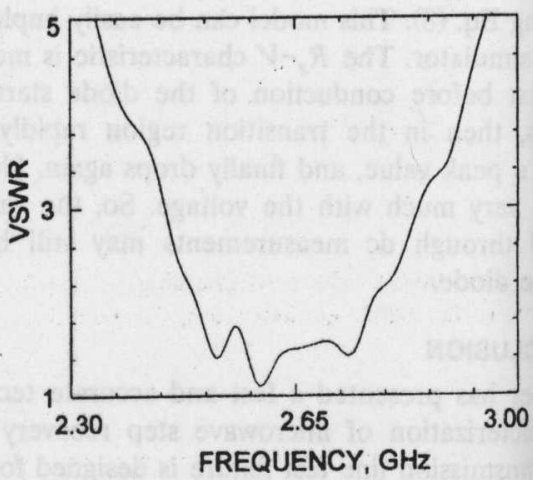

(a)

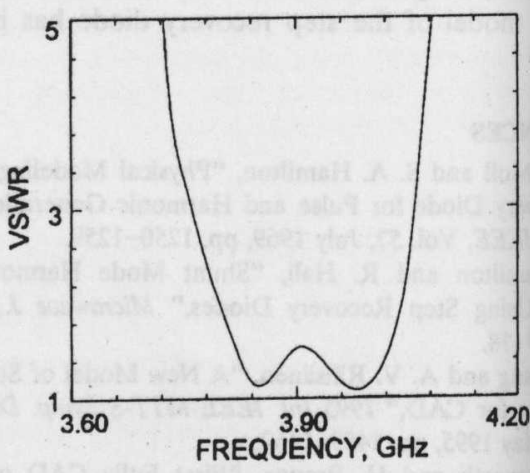

(b)

Figure 2 Variation of VSWR with frequency for the two pr antenna configurations. (a) Rectangular patch configuration. cular patch configuration 
through the DR center and the other through the feed point, is $135^{\circ}$.

The different characteristics for the above optimum antenna configurations are given in Table 2 for a comparative study.

The variation of VSWR with frequency for the two configurations is shown in Figure 2. The $E$-plane and $H$-plane radiation patterns of the antenna systems at the corresponding central frequencies are shown in Figure 3. In both cases, the $E$-plane patterns differ slightly from those of conven-

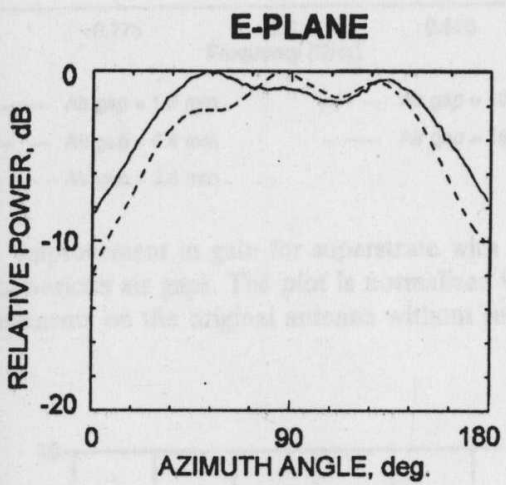

\section{H-PLANE}

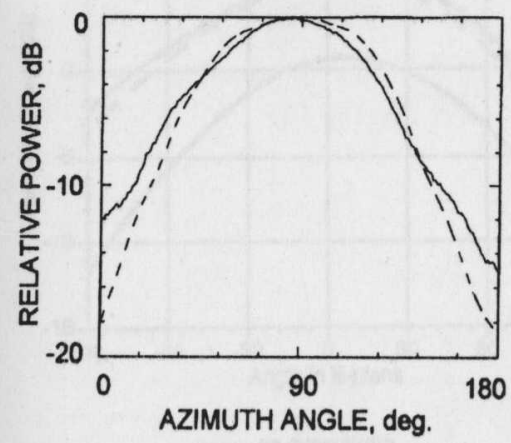

Figure $3 E$-plane and $H$-plane radiation patterns of the two antenna configurations at the corresponding central frequencies. Solid line: rectangular patch configuration. Dashed line: circular patch configuration

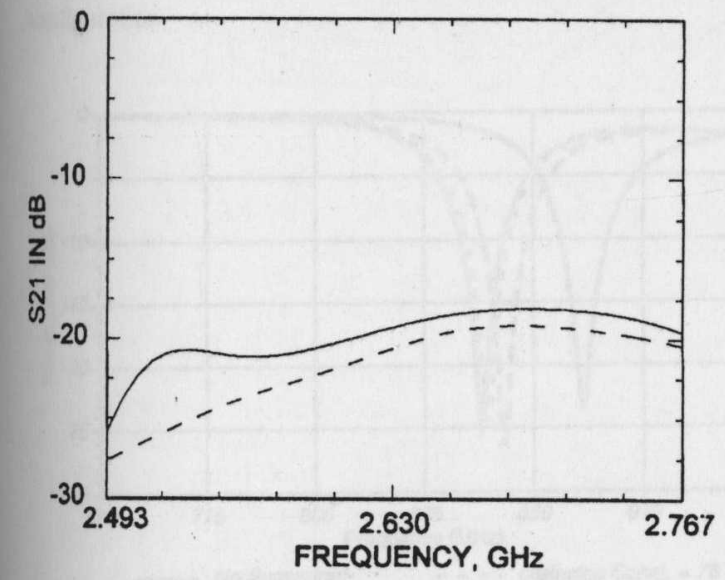

Figure 4 Variation of $S 21$ with frequency for the optimum rectangular patch configuration. Solid line: after DR loading. Dashed line: before DR loading 
tional microstrip antennas. $H$-plane patterns are similar to those of conventional ones. Figure 4 shows the variation of $S 21$ with frequency for the configuration shown in Figure 1. This figure shows that, compared to ordinary microstrip antennas, the present configuration gives an increased gain of $>1 \mathrm{~dB}$. This may be due to the reradiation from the DR.

\section{CONCLUSIONS}

A new method for enhancing the impedance bandwidth of microstrip antennas is proposed. This approach enhances the gain of the antenna, as well as enabling impedance tuning. Optimum rectangular (BW $>10 \%$ ) and circular (BW $>6 \%$ ) antenna configurations are demonstrated. These configurations may find applications in wideband phased arrays.

\section{ACKNOWLEDGMENT}

One of the authors, Jacob George, wishes to acknowledge the Council of Scientific and Industrial Research (CSIR), Government of India, for providing a research fellowship.

\section{REFERENCES}

1. H. Iwasaki and Y. Suzuki, "Electromagnetically Coupled Circular-Patch Antenna Consisting of Multilayered Configuration," IEEE Trans. Antennas Propagat., Vol. 44, June 1996, pp. 777-780.

2. C. K. Aanandan and K. G. Nair, "Compact Broadband Microstrip Antenna," Electron. Lett., Vol. 22, Oct. 1986, pp. 1064-1065.

3. G. Kumar and K. C. Gupta, "Non-Radiating Eges and Four Edges Gap-Coupled Multiple Resonator Broad-Band Microstrip Antennas," IEEE Trans. Antennas Propagat., Vol. AP-33, Feb. 1985, pp. 173-178.

4. S. Dey, C. K. Aanandan, P. Mohanan, and K. G. Nair, "A New Broadband Circular Patch Antenna," Microwave Opt. Technol. L.ett., Vol. 7, Sept. 1994, pp. 604-605.

5. I. J. Bahl and P. Bhartia, Microstrip Antennas, Artech House, Nonwood, MA, 1981.

(C) 1998 John Wiley \& Sons, Inc.

CCC $0895-2477 / 98$ 